\title{
The restraint chair: A qualitative study of nurses' experience with the restraint chair versus four point restraint
}

Nicole Visaggio

Kathryn Phillips

Fairfield University, kphillips1@fairfield.edu

Sharon Milne

Jeanne McElhinney

BGPdWGhiYoundgadditional works at: https://digitalcommons.fairfield.edu/nursing-facultypubs (c) 2020 Elsevier Inc. All rights reserved.

The author post-print has been archived here with permission from the copyright holder under a Creative Commons Attribution Non-Commercial No Derivatives License.

\section{Peer Reviewed}

\section{Repository Citation}

Visaggio, Nicole; Phillips, Kathryn; Milne, Sharon; McElhinney, Jeanne; and Young, Scott C., "The restraint chair: A qualitative study of nurses' experience with the restraint chair versus four point restraint" (2020). Nursing and Health Studies Faculty Publications. 234.

https://digitalcommons.fairfield.edu/nursing-facultypubs/234

\section{Published Citation}

Visaggio, Nicole, Kathryn E. Phillips, Sharon Milne, Jeanne McElhinney, and Scott C. Young. "The restraint chair: A qualitative study of nurses' experience with the restraint chair versus four point restraint." Archives of Psychiatric Nursing 34, no. 1 (2020): 2-6 https://doi.org/10.1016/j.apnu.2019.12.009

This item has been accepted for inclusion in DigitalCommons@Fairfield by an authorized administrator of DigitalCommons@Fairfield. It is brought to you by DigitalCommons@Fairfield with permission from the rightsholder(s) and is protected by copyright and/or related rights. You are free to use this item in any way that is permitted by the copyright and related rights legislation that applies to your use. For other uses, you need to obtain permission from the rights-holder(s) directly, unless additional rights are indicated by a Creative Commons license in the record and/or on the work itself. For more information, please contact digitalcommons@fairfield.edu. 
Running head: RESTRAINT CHAIR

Title: The restraint chair: A qualitative study of nurses' experience with the restraint chair versus four point restraint

\section{Authors:}

Nicole Visaggio, RN, BSN

McLean Hospital

115 Mill St. Belmont, MA 02478

NVISAGGIO@partners.org

Kathryn E. Phillips, PhD, APRN

Fairfield University

1073 N. Benson Road, Fairfield, CT 06825

617-686-4868

Kphillips1@,fairfield.edu

Sharon Milne, PhD, RN

McLean Hospital

115 Mill St. Belmont, MA 02478

and

Endicott College

376 Hale St.

Beverly, MA 01915

smilne@endicott.edu

Jeanne McElhinney, MS, RN-BC

McLean Hospital

115 Mill St. Belmont, MA 02478

JMCELHINNEY@partners.org

Scott C. Young, RN

McLean Hospital

115 Mill St. Belmont, MA 02478

SYOUNG9@partners.org 


\begin{abstract}
Restraint and seclusion continues to be a challenging topic in psychiatric nursing care. While there is a movement toward reduction and elimination of restraint, emergency situations still arise that require intervention for the safety of patients and staff. In addition to traditional methods of restraint (physical holds, four-point restraint, seclusion), the restraint chair has been introduced at some hospitals as an alternative to four-point restraint. The restraint chair allows the patient to be upright in a seated position during the restraint process. Little research on the restraint chair currently exists. The purpose of this study was to examine the nurses' experience with the restraint chair compared to four-point restraint. Results indicate nurses feel the restraint chair is easier to use, more humane, less traumatic, comforting, and enhances the therapeutic relationship compared to four-point restraint. Based on the reports of nurses in this study and prior quantitative work on the restraint chair (Castillo, Coyne, Chan, Hall, \& Vilke, 2011; Visaggio et al., 2018), the restraint chair appears to be a safe and effective alternative to traditional four-point restraint. More research verifying these results at other hospitals in the United States and abroad is warranted.
\end{abstract}

Key words: Restraint, safety, qualitative 


\section{Introduction}

The concept of restraint and seclusion within psychiatric care during emergency situations is one of ongoing debate, prompting the movement towards reduction and eventual elimination of its use. However, situations arise when nurses must decide whether to physically intervene when there is imminent risk or actual occurrence of harm to oneself or others. Both patients and staff agree that these situations of safety occur, and that restraint is a 'necessary evil' during these times (Wilson, Rouse, Rae, \& Ray, 2017). Given the risks involved in emergency situations, the focus continues to be on restraint reduction while working to find ways to restrain that maximize the safety of patients and staff at these difficult times.

Historically, restraints have included physical holds, seclusion within a locked room, and four-point restraints where the person is restrained to a bed in a supine position. Recently, some inpatient psychiatric units have implemented the restraint chair as a safe, evidence based

alternative to the aforementioned options during psychiatric emergencies (Visaggio et al., 2018). The restraint chair originated as a law enforcement tool that allows the patient to be restrained in an upright, seated position which may aid in respiration of the patient, a main safety concern when the patient is supine in four-points (Castillo, Coyne, Chan, Hall, \& Vilke, 2011; Vilke et al., 2011).

Although little evidence on the restraint chair exists in the literature, a review indicates that it is safe medically as long as proper monitoring procedures are followed (Castillo et al., 2011). More recent evidence from psychiatric facilities indicates staff injury rates are lower with the restraint chair than with four-point restraint while patient injury rates are similar between the two methods (Visaggio et al., 2018), indicating the restraint chair is at least as safe as four-point 
restraint. Given the evidence on safety, the restraint chair may offer an alternative to traditional four-point restraint.

\section{Background}

It is well documented that restraints should be a last resort, never punitively applied, and used only in situations where there is imminent danger (Goethals, de Casterle, Gastmans, 2012; McCain \& Kornegay, 2005). The decision to put hands on a patient during emergency situations is difficult for nurses to make (Goethals et al., 2012). In a qualitative study by Wilson and colleagues (2017), nurses described restraints as 'a necessary evil' and an 'unpleasant part of the job' that interferes with job satisfaction. Another study of staff experiences with restraint indicates restraints are a 'painful experience' (McCain \& Kornegay, 2005). Overall, the research indicates restraint is never easy for nurses and becomes an ethical dilemma that is "...unpleasant,

difficult, stressful, challenging, [and] risky...", while also something recognized as “...necessary to control aggressive behavior..." (Vedana et al. 2018). Given the risks and challenges, safer and more humane alternatives are needed to address situations of danger where safety is at risk (Vedana et al., 2018).

The experience of being restrained is also very difficult and carries psychological implications. Patients have described it as emotionally distressing and scary (Wilson et al., 2017). While patients feel powerless and that it impacts the therapeutic relationships with staff, they also state that it is necessary for maintaining safety (Wilson et al., 2017). Other studies have indicated patients report acts of coercion (which included restraint) made them "feel insecure, ...failing (as human beings), and having their integrity violated" (Olofsson \& Norberg, 2001). Although there is literature on the perspectives of staff and patients regarding restraint use, the authors know of no qualitative studies describing the nurse, staff, or patient experience 
of the restraint chair. The purpose of this study is to describe the psychiatric nurses' experience of using the restraint chair compared to traditional four-point restraints.

\section{Methods}

\section{Research Design}

An exploratory, qualitative approach was used to conduct this study. Three focus groups were conducted to gain better insight into understanding the psychiatric nurses' experience of using the restraint chair compared to traditional four-point restraint. Focus group methodology is helpful in discovering what people think, how they think, and why they think the way they do about the issues of importance to them without pressuring them into making decisions or reaching a consensus (Liamputtong, 2011, p.5). Some major advantages of using focus groups are efficiency and inducing thought provoking discussions.

\section{Population}

The target population was psychiatric registered nurses working at a large psychiatric hospital in the northeastern United States. Snowball sampling was used to recruit inpatient nurses. Snowball sampling "asks early informants to refer other study participants" (Polit \& Beck, 2012, p. 517). The advantage to using a purposive, snowball sample procedure was that it was efficient and practical. "Researchers may spend less time screening people to determine if they are appropriate for the study, with an introduction from the referring person, researchers may have an easier time establishing trusting relationships with new participants" (Polit \& Beck, 2012, p. 517). Using this sampling method, seven psychiatric nurses were recruited to participate in each of the three focus groups.

Inclusion criteria. Participants must have met the following inclusion criteria in order to participate in the study: 
- The participant must be a registered nurse (RN).

- The participant must be 18 years of age and currently working on an inpatient psychiatric unit.

- The participant must have utilized both the restraint chair and four-point restraints during their nursing career.

- The participant must be able to speak, read, and write in English.

Exclusion criteria. Participants excluded from the study were:

- Any participant who did not work on an inpatient, psychiatric unit.

- Any participant who has not used both the restraint chair and four-point restraints during their nursing career.

- Any participant who was not fluent in the English language.

- Any participant who did not hold an active RN licensure.

\section{Definitions}

Four-point restraints secure the patient by each limb onto a bed, in the supine position. Comparatively, the restraint chair secures the patient while in a seated position on a cushioned chair. These devices are used when least-restrictive alternatives have been exhausted and there is imminent risk or actual occurrence of harm to self or others. Staff continuously observe the patient and assess for readiness to be released. Restraints are released in the shortest amount of time possible.

\section{Data Collection Instruments}

A semi-structured interview guide was used to keep the participants focused and to implement consistency while questioning the participants. Participants were asked to consider the following questions about restraint use as it pertains to psychiatric nurses during emergency 
situations: 1, Please describe your experience with the use and type of restraints; 2, Please describe your nursing decision process on the use of different types of restraints; 3 , Please describe the patient experience of restraint, both four-points and the restraint chair, from your perspective. The development of these questions was aimed at maintaining an open dialogue on the experiences of the participants as it applies to restraint situations. Participants were also asked to complete a demographic sheet for descriptive purposes.

\section{Data Collection Procedures}

Three focus groups were conducted in a private conference room on hospital property. The groups were audio recorded with two digital, portable recorders and lasted approximately 30 to 40 minutes in length. Prior to conducting the interviews, informed consent was obtained from each of the participants. A professional medical transcriptionist transcribed each group audio recordings.

\section{Analysis}

Data analysis was conducted using the Classic Analysis Strategy (Krueger \& Casey, 2009). This process involves a "holistic review of the transcripts, preliminary coding of possible categories, followed by a more detailed process of creating categories of themes within the data" (Billups, 2012, p. 9). Krueger and Casey (2009) note, "The Classic Approach is a lowtechnology option that has been used in countless analysis projects. It allows the analyst to identify themes and categorize results" (p. 118). This method of analysis focuses on numbering each line of the transcript, printing the transcript, breaking down the transcripts by sequence and then coding each one. The coding process thus allows the researcher to then compile summaries and in turn begin to look for themes. 
Krueger and Casey (2009) suggest the researcher decides how much weight or emphasis to give the comments or themes. They also suggest looking at several factors: "frequencyAlthough we pay attention to how frequently something is said, it is a mistake to assume that what is said most frequently is most important. Sometimes a key insight might have been only said once in a series of groups" (Krueger \& Casey, 2009, p. 121).

The next factor is specificity. "Typically we consider giving more emphasis to comments that are specific- that give detail” (Krueger \& Casey, 2009, p. 121). The last two factors Krueger and Casey (2009) suggest assessing for are emotion and extensiveness. With emotion, the researcher typically tends to "give more weight to comments or themes where participants show emotion- Enthusiasm, passion, or intensity in their responses” (Krueger \& Casey, 2009, p. 121). Extensiveness is a key component different from frequency, in that it is not the number of times someone says something, but rather "how many different people said something" (Krueger \& Casey, 2009, p. 121).

Once the narratives were completed and themes were extrapolated from the data, the researchers then looked at the original research questions and the summaries for each in order to determine if any of the themes cut across any of the other questions (Krueger \& Casey, 2009). Upon completion of the data analysis, the interpretations and recommendations of the findings were solidified and described in preparation for dissemination.

\section{Results}

\section{Demographics}

A total of 21 registered nurses (RNs) participated in the study with an average age of 41.62 (SD 13.6) years. One of the 21 participants also held an Advanced Practice Registered Nurse (APRN) license in addition to their RN license. The majority of participants were female 
(85.71\%) and had a bachelor's degree (66.67\%), while $23.81 \%$ had an associate's degree and $9.52 \%$ had a master's degree. They reported working an average of 14.26 (SD 14.3) years in nursing with 11.24 (12.04) years in psychiatric nursing. Most worked full time (42.86\%), with $33.33 \%$ working part time and $23.81 \%$ working per diem. The primary diagnoses of the patients the nurses reported working with included: schizophrenia (52.38\%), bipolar disorder (61.9\%), depression (33.33\%), psychotic disorders (33.33\%), anxiety (14.29\%), and $4.76 \%$ from each of the following: post-traumatic stress disorder, borderline personality disorder, "suicidal patients", and "full range of diagnoses."

\section{Qualitative Results}

Qualitative results fell into three categories: the nurses' decision to restrain, the chair versus four-point restraint, and the patient experience of restraint. Under each of these categories, the authors found several themes that became prominent in the discussion.

\section{Nurses' decision to restrain.}

Under the category of the 'nurses decision to restrain' three themes emerged from the focus group discussions: safety, last resort, and tough decision.

\section{Safety.}

In the decision to restrain, the issue of safety came up frequently. Nurses spoke about how "restraints really cannot be for anything else other than safety." Others used more detail to discuss who's safety they were referring to with comments like, “...if the patient, other patients, staff are in danger in any way, if the patient becomes assaultive, then it's safer to go with the chair and/or four-points ..."“

\section{Last resort.}


When deciding to use restraint, nurses talked about how this is the method of 'last resort." Others described how they try other interventions first, “. . I was impressed with our ability to deescalate and avoid a restraint unless it was the last option..." and "...I know that we've exhausted all medications and skills and coping and then we just make the decision that it has to be done.... You just kind of really have nothing else to do and it seems like the most helpful decision."

\section{Tough decision.}

The use of restraints is something nurses described as an arduous decision due to the repercussions involved. One nurse stated, “. . . it's a lot of pressure. . . . the pressure of that responsibility..." Another described the difficult decision as, “ . . . it's tough because where that line is, there are so many factors involved and it's tough to make that call sometimes." While another talked about the experience of choosing to use restraint as “... it's also a very invasive

thing to do, to actually, touch somebody, to restrain somebody ..." Meanwhile another noted the repercussions of the decision to restrain, “. . . it's such a huge responsibility, you know, it's a very traumatic event both psychiatrically and medically, anytime somebody is either taken down in a restraint or put in four-points."

\section{The chair compared to four-point restraints.}

When nurses were asked to compare the chair to four-point restraints, five themes were noted whereby the chair was an improvement over four-point restraints. The themes included the chair being easier to use, more humane, less traumatic, comforting, and enhancing the therapeutic relationship. There was one situation where nurses noted four-points were more useful, when the patient was already supine.

\section{Easier to use.}


Many nurses mentioned how much easier it is to use the chair in situations of restraint. They noted cases of bringing the chair to the patient, “... being allowed to bring the chair to a patient is a huge advantage, especially with patients who are attempting self-injury." Nurses also spoke about the improved safety for patients in the chair with less risk of injury for patients and staff: ". . . how much more streamlined the process is with the chair . . just thinking back to . . . staff injuries and patient injuries. .." Others noted that less physical force is needed to restrain patients when using the chair, "I can actually ... move it around and I think it's less reliant on physical force in order to restrain and contain the situation, and for that I feel like it's safer." Finally, nurses indicated that there is a faster path to securing the straps in the chair compared to four-point restraints, “...patients are unable to wiggle out as much. And the straps and what needs to secure a patient is put in place very quickly which allows the patient to de-escalate ... more quickly."

\section{Enhances therapeutic relationship.}

Another benefit of the chair compared to four-point restraints noted by nurses was that the chair allowed for an enhanced therapeutic relationship and communication between the patient and nurse. Some spoke about the power and control involved in restraint and how the chair breaks down that barrier. Comments included ". . . you build this relationship that isn't so much about this kind of power struggle where I have all the power." Other nurses talked about being on the same physical level with the patient and the impact this has on the situation. They explained it as follows: "I think the fact that we can put someone in the chair and speak with them eye-to-eye, we keep them as our peer, not just as a patient," and "One thing I really like about the chair is once a person's in that chair, you're in this process of having a dialogue with them as they're ... calming down ... When you're sitting with them eye to eye, even though 
they're strapped down it's not the same sense of hovering over somebody who's splayed across a bed in four-points ..."

\section{Humane.}

A common word used by nurses in the study to describe the difference between the restraint chair and four-point restraints was 'humane'. Others spoke about the difference between the chair and four-points with descriptions like, “... the switch to the chair, which for me feels much more humane ...." and "...we got the restraint chair and I thought it was a game changer. I felt it . . . provided the patient with more dignity and respect."

\section{Less Traumatic.}

When thinking about restraining a patient, nurses talked about how this can be traumatic for them and for the patients. They also discussed how many patients have trauma backgrounds and restraint can trigger trauma memories. When thinking about the chair and four-points from a trauma perspective, they indicated the chair was less traumatizing. “...I remember thinking about that with four-points and thinking how really awful that is, how vulnerable.” and " . [ [the restraint chair] leaves them in a less vulnerable position than when they're lying on a bed." Finally, a nurse noted how there are less staff needed to restrain a patient with the chair, they stated "...I think the patient also feels better when we don't have to have . . . dozens of people around and it's not ... drawn out and escalated beyond where it needs to be."

\section{Comforting.}

The last theme to emerge as a benefit of the restraint chair over four-points was the idea that the chair can sometimes serve as a comfort to patients who are out of control. "... people have explicitly said - I'd like to stay in the chair. . . like they find it almost comforting." Another nurse specifically stated, “...the overhead strap. It actually, kind of works like a 
weighted blanket for some of our patients that have struggled with trauma or have a hard time de-escalating because some of them kind of have asked to go into the chair briefly..."

\section{Four-points for supine.}

Although most comments from the nurses in the study were around the benefits of the chair compared to four-point restraint, there was one situation that was noted when nurses felt that four-point restraints were a benefit over the chair, when the patient is already supine. Nurses spoke about how easy it is to use four-points when they are already supine, compared to switching positions in order to get the patient into the chair. One nurse described it well, "If the patient is already on the ground, ... we can't lift the patient's weight without them doing it ..."

\section{Patient experience of restraint.}

When nurses were asked to consider the patient response to restraint, four themes emerged: fear, anger, thankful, and remorse. Answers to this thought provoking question were arranged by the timing, whether we were discussing the patient experience during the restraint process or following restraint use. For instance, nurses noted that during the restraint, patients appear fearful and angry whereas after the restraint they are thankful and full of remorse.

\section{Fear.}

Nurses noted patients often appear to be fearful during the restraint process. "They have to be fearful of what's going on, our patients who have no sense of their surroundings, suddenly five, six people are grabbing hold of them, like you're saying." Another nurse stated, "But it sounds like from what other patients say in regards to the possibility of being strapped down on a bed or something like that, they would say there's a lot of fear..."

Anger. 
Anger was another common theme nurses indicated patients experience during the restraint process. "I think a lot of times what patients are experiencing is like probably anger ... .which is very understandable.” Another nurse told a story of a patient who, “...was really agitated. You could just tell that inside she was so frustrated and she just kept asking for a tranquilizer in her words . . . the feeling of that level of agitation must be incredibly uncomfortable..."

\section{Thankful.}

Nurses indicated patients will thank them for the restraint because they were out of control at the time, "And he looked up at me and he said - thank you so much. And I'll never forget that. And so he knew that he had lost control." Another nurse recounted several experiences where this has happened, "I want to say I've been thanked multiple times by people in restraints for putting them in restraints, shockingly, it has happened." While another described experiences where, “...we do often have patients that do express gratitude. ... They're sorry and they're glad that we kept them from harming themselves and harming staff as well."

\section{Remorse.}

Finally, nurses indicated patients apologize for their behavior during the restraint process after the incident occurs. '. . . There is a lot more reflection, sometimes crying and apologies and we're able to kind of reflect on the behavior that led to the restraint situation." Other nurses discussed how patients only sometimes remember what their behavior was like at the time of restraint describing it as, “... if they remember, pretty much every time . . they'll make a comment to me and say, 'Hey, I'm so sorry for the way I acted a couple days ago'..."

\section{Discussion}


This is the first study to consider the nurse's perspective of using the restraint chair compared to four-point restraints. The main themes noted when discussing use of the restraint chair during psychiatric emergencies was: easier to use, enhances therapeutic relationship, humane, less traumatic, and comforting. These themes highlight the fact that the chair can be easily moved to the location where the patient is, it is easily used by a small number of staff, and it reduces risk of injury when compared to four-point restraint. Prior research has indicated the chair resulted in no more injuries to patients when compared to four-point restraint or seclusion, while staff injuries were highest with four-point restraint when compared to the two other methods (Visaggio et al., 2018). These are salient points when considering the type of restraint to use in a stressful situation where safety is of highest importance.

Nurses in this study also commented on how the upright position of the chair enhances the therapeutic relationship, allowing the nurse and patient to be equals on eye level with each other, rather than the nurse hovering over the patient when they are supine in four-point restraints. The fact that the chair is noted to enhance the therapeutic relationship is a key point since prior qualitative studies have noted how detrimental restraint is to the staff-patient relationship (Wilson et al., 2017). Additionally, patient interviews from psychiatric care indicate the patients' desire to know the staff and have a relationship with them (Olofsson \& Norberg, 2001).

The upright position of the restraint chair was also noted by nurses in this study to be less traumatic to the patient, allowing the patient to be in a less vulnerable position during restraint compared to four-point restraint where they are supine. Another important point not noted by nurses in this study, but found in the literature regarding the restraint chair and the upright position is in regard to the ease of ventilation when upright. In the only known human study 
measuring the ventilatory effects of the restraint chair, results indicated there was only a small decrease in maximal voluntary while there were no changes in oxygen saturation or end tidal carbon dioxide $\left(\mathrm{PETCO}_{2}\right)$ (Vilke et al., 2011).

Another theme noted by nurses in line with the restraint chair enhancing the therapeutic relationship and being less traumatic is the idea that it's more humane, due to the fact that the patient is in a seated position and is able to make eye-contact with staff. This is in sharp contrast to themes noted by nurses in other studies showing how restraint is 'dehumanizing' and that it negatively affects the 'quality of patient-staff relationships' (Wilson et al., 2017). Finally, some nurses commented on the fact that the chair can actually be comforting for some patients, similar to a weighted blanket. These points indicate the restraint chair may be a helpful way to address situations where safety is a concern while maintaining the nurse-patient relationship and the dignity of the patient.

The results from this paper regarding nurses' decision to restrain are similar to prior studies. A metaanalysis of qualitative literature about the decision to restrain indicated that nurses feel the use of restraint is a "complex" decision that is really focused on "safety" while balancing the "ethical" concerns of the situation (Goethals et al., 2012). In another study of nurses and patients, restraint was referred to as a "necessary evil" that is difficult for patients and staff, yet both parties realize it is essential to have as a last resort for safety (Wilson et al., 2017). These studies results are similar to the themes nurses in this study stated, including the idea that the decision to restrain is a tough decision, focused on safety, and only used as a last resort when other interventions have been exhausted.

Although this study did not interview patients, the nurses were asked to consider the experience of restraint for the patient. Themes that emerged around this question match prior 
work that interviewed patients (Wilson, Rouse, Rae, \& Ray, 2018, Wilson et al., 2017). Nurses in this study felt patients experienced fear and anger during the restraint process, which is in line with some of the emotional outcomes of distress and fear noted by patients and staff in a prior study of patient and staff experiences with restraint by Wilson and colleagues (2017). The study by Wilson and colleagues (2017) also noted emotional reactions of distress and dehumanizing which did not emerge here. Finally, there were two additional themes discussed by nurses in this study that the authors have seen only limited discussion of in the qualitative literature on restraint, the idea that patients express gratitude for the experience of restraint and that patients are often remorseful after the restraint. The authors found only one study noting two patients reporting that coercive actions (which included restraint) were "good and necessary for them initially" (Olofsson \& Norberg, 2001). Timing of interviews with patients and staff following episodes of restraint, the way questions are asked in a qualitative interview, and the type of qualitative inquiry may have resulted in these themes emerging in this study that were not noted in others.

\section{Strengths and Limitations}

Since the study was conducted at one free standing psychiatric hospital in the northeastern United States, these findings have limited generalizability. However, this is the first study to qualitatively assess nurses' experiences with the restraint chair compared to four-point restraint and adds valuable information to the research literature on the restraint chair, which is extremely sparse.

\section{Future Directions for Research}

It would be helpful to have replication studies at other hospitals in different parts of the country as well as outside the United States because this is the first study to explore nurses' 
experience of the restraint chair compared to four-point restraint. Additionally, no literature exists on the patient experience of the restraint chair or comparing the patient experience of the restraint chair to four-point restraint. A study that qualitatively assessed patients' experiences of the chair would be a significant addition to the literature.

\section{Conclusion}

Based on the reports of nurses in this study and prior quantitative work on the restraint chair (Visaggio et al., 2018), the restraint chair appears to be a safe and effective alternative to traditional four-point restraint. More research verifying these results at other hospitals in the United States and abroad is warranted. 


\section{References}

Billups, F. D. (2012). Conducting focus group with college students: Strategies to ensure success [White paper]. Tallahassee, FL: Association for Institutional Research.

Castillo, E. M., Coyne, C. J., Chan, T. C., Hall, C. A., \& Vilke, G. M. (2015). Review of the medical and legal literature on restraint chairs. Journal of Forensic and Legal Medicine, 33, 91-97.

Goethals, S., de Casterle, B. D., \& Gastmans, C. (2012). Nurses' decision-making in cases of physical restraint: A synthesis of qualitative evidence. Journal of Advanced Nursing, 68(6), 1198-1210. Doi: 10.1111/j.1365-2648.2011.05909.x

Krueger, R. A., \& Casey, M. A. (2009). Focus groups: A practical guide for applied research. Thousand Oaks, CA: SAGE.

Liamputtong, P. (2011). Focus group methodology: Introduction and history. Thousand Oaks, CA: SAGE.

McCain, M., \& Kornegay, K. (2005). Behavioral health restraint: The experience and beliefs of seasoned psychiatric nurses. Journal for Nurses in Staff Development, 21(5), 236-242.

Olofsson, B., \& Norberg, A. (2001). Experiences of coercion in psychiatric care as narrated by patients, nurses and physicians. Journal of Advanced Nursing, 33(1), 89-87.

Polit, D. F., \& Beck, C. T. (2012). Nursing research: Generating and assessing evidence for nursing practice $\left(9^{\text {th }}\right.$ ed.). Philadelphia, PA: Wolter Kluwer | Lippincott Williams \& Wilkins.

Wilson, C., Rouse, L., Rae, S., Ray, M. K. (2017). Is restraint a 'necessary evil' in mental health care? Mental health inpatients' and staff members' experience of physical restraint. International Journal of Mental Health Nursing, 26, 500-512. 
Wilson, C., Rouse, L., Rae, S., \& Ray, M. K. (2018). Mental health inpatients' and staff members' suggestions for reducing physical restraint: A qualitative study. Journal of Psychiatric and Mental Health Nursing, 25, 188-200. doi: 10.1111/jpm.12453

Vedana, K. G. G., da Silva, D. M., Ventura, C. A. A., Giacon, B. C. C., Zanetti, A. C. G., Miasso, A. I., \& Borges, T. L. (2018). Physical and mechanical restraint in psychiatric units: Perceptions and experiences of nursing staff. Archives of Psychiatric Nursing, 32, 367-372. https://doi.org/10.1016/j.apnu.2017.11.027

Vilke, G. M., Sloane, C., Castillo, E. M., Kolkhorst, F. W., Neuman, T. S., \& Chan, T. C. (2011). Evaluation of the ventilatory effects of a restraint chair on human subjects. The Journal of Emergency Medicine, 40(6), 714-718. doi: 10.1016/j.jemermed.2009.12.002

Visaggio, N., Phillips, K. E., Kichefski, K., McElhinney, J., Idiculla, T. B., Blair, E. W., ... Young, S. (2018). Is it safe? The restraint chair compared to traditional methods of restraint: A three hospital study. Archives of Psychiatric Nursing, 32, 723-728. https://doi.org/10.1016/j.apnu.2018.04.003 